\title{
The Neuropathies of Waldenström's Macroglobulinemia (WM) and IgM-MGUS
}

\author{
Christopher J. Klein, Joon-Shik Moon, Michelle L. Mauermann, \\ Steven R. Zeldenrust, Yanhong Wu, Angela Dispenzieri, Peter J. Dyck
}

\begin{abstract}
Background: Neuropathy is common in Waldenström's macroglobulinemia (WM, an IgM-associated lymphoplasmacytic lymphoma) and in IgM-monoclonal gammopathy of undetermined significance (IgM-MGUS). Paraneoplastic or paraimmune mechanisms are thought to be involved in the pathogenesis of these neuropathies. Attempts at distinguishing WM and IgM-MGUS neuropathies are lacking especially among bone marrow (BM) confirmed patients. Methods: Retrospective analyses were performed on BM confirmed WM $(\mathrm{N}=30)$ and IgM-MGUS $(\mathrm{N}=73)$ neuropathy patients with neurologic assessments and hematologic features. Results: The presence of anemia and quantity of $\operatorname{IgM}$ monoclonal protein were significantly greater in WM. Based on multiple neurologic assessments differences were not found for: 1) length of time from neurologic symptom onset to evaluation; 2) chief complaint of painless loss of feeling in the feet, Romberg's sign and tremor; and 3) clinical motor, sensory and reflex abnormalities. Autonomic testing was normal in both diseases. Using nerve conduction (NCS) criteria for demyelination, 62\% of IgM-MGUS and $27 \%$ of WM met this criteria ( $\mathrm{p}=0.013$ ). IgM MGUS patients had greater terminal conduction slowing by ulnar residual latency calculation $(<0.01)$. The degree of axonal loss as measured by summated compound muscle action potentials and available nerve biopsy was not significantly different between diseases. Conclusion: Although WM and IgM-MGUS must be distinguished for hematologic prognosis and treatment, clinical neuropathy presentations of WM and IgM-MGUS are similar and likely related to comparable axonal loss in both conditions. Despite these similarities, evidence of demyelination was found by electrophysiologic studies much more commonly in IgM-MGUS. This difference may reflect varied immune mechanism(s) in the two disorders.
\end{abstract}

RÉSUMÉ: Les neuropathies de la macroglobulinémie de Waldenström et de l'IgM-MGUS. Contexte : La neuropathie est fréquente dans la macroglobulinémie de Waldenström (MW), un lymphome lymphoplasmocytaire associé à IgM, et dans la gammopathie monoclonale IgM de signification indéterminée (IgM-MGUS). Des mécanismes paranéoplasiques ou paraimmuns seraient impliqués dans la pathogenèse de ces neuropathies. Aucune tentative de faire la distinction entre les neuropathies de MW et d'IgM-MGUS n'a été effectuée dans le passé, particulièrement chez les patients dont le diagnostic a été confirmé par un prélèvement de moelle osseuse (MO). Méthode : Des analyses rétrospectives ont été faites chez les patients atteints de neuropathie, dont le diagnostic de MW $(n=30)$ et d'IgM-MGUS $(n=73)$ avait été confirmé sur la MO et qui avaient subi des évaluations neurologiques et hématologiques. Résultats : L'anémie et la protéine monoclonale IgM étaient significativement plus importantes dans la MW. Aucune différence n'a été observée dans les multiples évaluations neurologiques concernant : 1) l'intervalle entre le début des symptômes neurologiques et l'évaluation ; 2) le symptôme principal, soit la perte de sensibilité au niveau des pieds, le signe de Romberg et le tremblement ; 3 ) les anomalies cliniques motrices, sensitives et des réflexes. L'évaluation du système nerveux autonome était normale dans les deux maladies. La conduction nerveuse a été évaluée selon les critères utilisés pour détecter la démyélinisation : $62 \%$ des patients atteints d'IgM-MGUS et $27 \%$ des patients atteints de MW rencontraient ces critères $(\mathrm{p}=0,013)$. Les patients atteints d'IgM-MGUS avaient un ralentissement plus important de la conduction terminale au calcul de la latence résiduelle cubitale $(<0,01)$. Le degré de perte axonale tel que mesuré par sommation des potentiels d'action musculaire composés et la disponibilité d'une biopsie nerveuse n'étaient pas significativement différents chez les deux groupes de patients. Conclusion : Nous n'avons pas observé de différence significative dans les symptômes et les signes de neuropathie entre les patients atteints de MW et ceux atteints d'IgM-MGUS que nous avons étudiés. Les ressemblances cliniques sont vraisemblablement reliées à une perte axonale comparable dans ces deux maladies. Malgré ces ressemblances, des signes de démyélinisation ont été notés à l'électrophysiologie beaucoup plus fréquemment chez les patients atteints d'IgM-MGUS. Il est possible que cette différence soit reliée à un ou des mécanismes immunologiques différents dans les deux maladies.

Can J Neurol Sci. 2011; 38: 289-295

In the evaluation of a patient with peripheral neuropathy the discovery of a serum monoclonal protein has implications for the neurologic and hematologic diagnosis, prognosis and treatment ${ }^{1}$. Among such patients the type of neuropathy may suggest the specific underlying hematologic process. To illustrate, in a patient with a monoclonal protein having subacute painful multiple mononeuropathies the diagnosis of mixed cryoglobulinemia is likely and evaluation for viral hepatitis should be emphasized. In another patient, also with a monoclonal protein and with insidious onset of a symmetric painful autonomic, sensory motor polyneuropathy, primary amyloid light chain (AL) amyloidosis should be suspected. In a third example a

From the Peripheral Nerve Research Laboratory (CJK, JSM, MLM, PJD), Department of Hematology (SRZ, AD), Department of Laboratory Medicine and Pathology (YW), Mayo Clinic, Rochester, Minnesota, U.S.A

Received August 27, 2009. Final Revisions Submitted October 14, 2010. Correspondence to: Christopher J. Klein, Department of Neurology, Mayo Clinic, 200 First Street SW, Rochester, Minnesota, 55905, U.S.A 
monoclonal protein with insidious demyelinating polyradiculoneuropathy occurs in POEMS (Polyneuropathy, Organomegaly, Endocrinopathy, M spike and Skin changes) and should lead to search of treatable osteosclerotic myeloma ${ }^{2}$. Familiarity of these patterns, and others, leads to correct diagnosis and treatment.

Among persons having IgM-MGUS an insidious painless distal sensory ataxic neuropathy with demyelination has been felt to be so characteristic as to coin the acronym DADS (Distal, Acquired, Demyelinating, Sensory-neuropathy) ${ }^{3}$. By contrast descriptions of the neuropathy features occurring in another IgM condition, namely Waldenström's macroglobulinemia (WM) are limited ${ }^{4,5}$. Waldenström's macroglobulinemia is defined by the Revised European American Lymphoma (REAL) and World Health Organization (WHO) as having a bone marrow (BM) infiltrated lymphoplasmacytic lymphoma and IgM paraproteinemia ${ }^{6}$. In WM the hematologic features of anemia, hepatosplenomegaly, lymphadenopathy, and hyperviscosity have previously been reported but are variably present with current requirement of BM diagnosis ${ }^{7}$.

Some investigators have suggested there are more axonal features in the nerve conduction studies (NCS) in WM, but the diagnosis of WM did not appear to be based on current BM criteria ${ }^{4,5}$. By contrast, distal, symmetric, chronic demyelinating neuropathy is more commonly described in IgM-MGUS neuropathy patients ${ }^{3,8}$ including the reports of reduced terminal latency index (TLI), indicating relative slowing in distal motor nerve segments ${ }^{9-11}$. Tremor has also been described to be one of the possible clinical stigmata of the IgM-MGUS neuropathy ${ }^{12}$. Some studies have suggested that the existence of myelinassociated glycoprotein antibodies (anti-MAG) may explain the clinical, electrophysiologic, and histologic features of the DADS-IgM-MGUS neuropathy ${ }^{13-15}$. However, other studies of IgM neuropathy have found little or no difference between the type and severity of neuropathies in IgM patients with or without anti-MAG antibodies ${ }^{16,17}$. The MAG antibodies are commonly present in IgM amyloid neuropathy and IgM patients without neuropathy and therefore are not routinely used for diagnosis at many institutions including our own ${ }^{18}$.

We conducted this retrospective review to characterize the neuropathies associated with WM and IgM-MGUS to answer whether there are clinical, electrophysiologic and nerve biopsy findings that distinguish the neuropathies associated with WM from IgM-MGUS. In an attempt to study distal predominant involvements we use the previously published formulas to calculate the residual latency (RL) and TLI from routine NCS. The $\mathrm{RL}^{19}$ is a subtraction of the calculated latency from the measured latency. It evaluates the distal segment of the motor nerves and has been reported to be associated with the neuropathy associated with IgM-MGUS ${ }^{20}$. The TLI is the ratio between the calculated latency [distance/motor conduction velocity $(\mathrm{MCV})]$ and the measured latency, i.e. distal motor latency (DML) and also assesses for selective distal conduction velocity slowing ${ }^{9-11,21}$.

\section{Methods}

\section{Subjects}

With the approval of our institutional review board, an electronic record retrieval system was used to identify patients diagnosed with either WM or IgM-MGUS, who had peripheral neuropathy and had undergone NCS testing between January, 1973 and December, 2007. Hematology and neurology consultation with complete neurologic examination by specialists working in peripheral nerve disease was required for inclusion of cases. Possible hereditary motor and sensory neuropathy cases and cases with other acquired etiologies other than IgM-associated cause were excluded ${ }^{22,23}$. This included clinical evaluation and laboratory testing for diabetes, thyroid disease, kidney disease, infectious hepatitis and alcoholic neuropathy. Detailed family histories had been obtained as part of our routine practice to exclude inherited peripheral neuropathies. Also excluded were cases of amyloidosis and POEMS syndrome. No patients had amyloid on bone marrow biopsy and none had systemic sequelae of POEMS syndrome, all having undergone metastatic bone survey in exclusion of osteosclerotic myeloma. Only patients with NCS before neurotoxic or immunosuppressant therapies were studied in both WM and IgM-MGUS.

Bone marrow biopsy, hematologic parameters (levels of hemoglobin, IgM and other monoclonal proteins, platelets, creatinine, light chains), sural nerve biopsies, autonomic testing, ${ }^{24,25}$ neurologic examinations including neuropathy impairment score (NIS) ${ }^{26}$ with individual motor, reflex, and sensory parameters were examined. Other features were also extracted from the records including presenting complaint, presence of tremor, age, sex, and length of symptoms to the time of NCS. The hematologic and clinical parameters were reviewed at the time of NCS.

\section{Diagnosis of WM and IgM-MGUS}

Bone marrow diagnosis of WM was based on the WHO classification by which lymphoplasmacytic cells must be seen diffusely without myeloma or other lymphomatous disorders present $^{6}$. Diagnosis of WM or IgM-MGUS with bone marrow biopsy was made by hematologists and hematopathologists using the standard approach ${ }^{6}$. All patients had positive immunofixation for IgM-MGUS and simultaneously performed serum protein electrophoresis. We chose to include only BM confirmed IgM-MGUS to exclude inclusion of occult WM for this research study.

\section{Nerve Conduction Study (NCS)}

Nerve conduction study were performed by uniform technique by experienced and certified technicians, previously on Teca-TD20 and subsequently on Nicolet Viking with similar filter settings and electrode placement and stimulation technique ${ }^{27}$. Skin temperature was measured at the dorsum of hand or foot, which was maintained above $32^{\circ} \mathrm{C}$ with electrode placement and stimulation similar between all patients. Using our standard peripheral neuropathy protocol, motor nerve conductions were reviewed in three motor (peroneal, tibial and ulnar) and two sensory (sural, median) nerves available in all 
patients. Median motor studies were also available among $8 \mathrm{WM}$ and 32 IgM-MGUS patients, and done typically in evaluation of superimposed mononeuropathy. Normal values were defined based on standards set at the electromyelogram (EMG) laboratory at Mayo Clinic, Rochester, MN, USA. Demyelination and axonal features were determined by standard criteria ${ }^{28}$ widely used in research and clinical practice, i.e. demyelination if; 1) Reduction in conduction velocity in two or more nerves; $<80 \%$ of lower limit of normal (LLN) if amplitude $>80 \%$ of the LLN, $<70 \%$ of LLN if amplitude $<80 \%$ LLN; 2) Partial conduction block or abnormal temporal dispersion in one or more nerves; $<15 \%$ change in duration between proximal and distal segments or $>20 \%$ drop in negative peak area or peak-topeak amplitude between proximal and distal sites; 3) And/or presence of one of these findings; a) Prolonged distal latencies in two or more nerves; $>125 \%$ of upper limit of normal (ULN) if amplitude $>80 \%$, or $>150 \%$ of ULN if amplitude $<80 \%$ of LLN; b) Absent $\mathrm{F}$ waves or prolonged minimum $\mathrm{F}$ wave latency; $>120 \%$ of ULN if amplitude is $>80 \%$ of LLN or $>150 \%$ of ULN if amplitude is $<80 \%$ of $\mathrm{LLN}^{28}$.

Terminal latency index was calculated on motor studies. The TLI is the ratio between the calculated latency [distance/motor conduction velocity] and the measured latency, i.e. distal motor latency $^{21}$ and was determined by the previously published formula: $\mathrm{TLI}=(1 / \mathrm{DML}$ (milliseconds) $\mathrm{x}$ (distal conduction distance(millimeters)/distal MCV(meters/ second)). Motor studies with no response were not included in the calculation of TLI and RL calculations. Terminal latency index was used to compare the wrist-to-thenar muscle (distal segment) with the elbow-to-wrist conduction velocity in median nerve, the wrist- to-hypothenar muscle (distal segment) with the elbow-to-wrist conduction velocity in ulnar nerve, the ankle-to-extensor digitorum brevis muscle (distal segment) with the knee-to-ankle conduction velocity in common peroneal nerve, and the ankleto-abductor hallucis muscle (distal segment) with the knee-toankle conduction velocity in posterior tibial nerve.

Residual latency considers differently the distal motor axonal slowing and was determined on available NCS attributes. Residual latency is a subtraction of the calculated latency (distance/MCV) from the measured latency (DML) and was determined by the previously published formula ${ }^{19}: \mathrm{RL}=\mathrm{DML}$ (ms) - [distal conduction distance $(\mathrm{mm}) /$ distal MCV $(\mathrm{m} / \mathrm{s})]$. This calculation was derived from the same NCS studied for TLI.

\section{Ascertainment of Axonal Loss}

To assess the degree of nerve fiber loss in motor and sensory nerves, percentiles were used to compare summated compound motor unit potentials (peroneal, tibial, ulnar) and summated sensory nerve action potential (sural and median) between WM and IGM-MGUS ${ }^{29-31}$. This approach was chosen in order to allow for comparison of axonal loss between individuals of different ages, heights, weights and gender correcting to a comparison of normal. Axonal involvement was also examined by needle examination standard techniques in muscles comparably examined in all patients (tibialis anterior, medial gastrocnemius, vastus medialis) using summated abnormalities of fibrillations or motor unit potential amplitudes, motor unit duration and recruitment with which a composite abnormality was created. The Mayo needle EMG classification scheme of

Table 1: Clinical characteristics of WM compared to IgM-MGUS

\begin{tabular}{|c|c|c|c|c|}
\hline \multicolumn{2}{|l|}{ 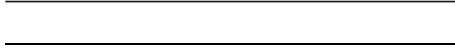 } & WM $(\mathrm{N}=30)$ & IgM-MGUS ( $N=73)$ & p-value \\
\hline \multicolumn{2}{|l|}{ Age (yrs.) } & median 65.5, range $46-82$ & median 64.0 , range $31-82$ & 0.821 \\
\hline Gender & $\begin{array}{l}\text { Yale } \\
\text { emale }\end{array}$ & $\begin{array}{r}22(73 \%) \\
8(27 \%)\end{array}$ & $\begin{array}{l}53(73 \%) \\
20(27 \%)\end{array}$ & 0.939 \\
\hline \multicolumn{2}{|c|}{ NIS at time of NCS (points) } & median $=17.5$, range $0-75$ & median $=24$, range $0-92$ & 0.055 \\
\hline \multirow{2}{*}{$\begin{array}{l}\text { Chief first complaint } \\
\text { number abnormal } \\
\text { (percent) }\end{array}$} & $\begin{array}{l}\text { "Numb toes \& } \\
\text { feet" }\end{array}$ & $28(93 \%)$ & $66(90 \%)$ & 0.633 \\
\hline & "Tremor" & $2(7 \%)$ & $7(10 \%)$ & 0.633 \\
\hline \multicolumn{2}{|c|}{$\begin{array}{l}\text { Romberg's' sign } \\
\text { number abnormal (percent) }\end{array}$} & $9(30 \%)$ & $29(41 \%)$ & 0.352 \\
\hline \multicolumn{2}{|c|}{$\begin{array}{l}\text { Tremor by examination } \\
\text { number abnormal (percent) }\end{array}$} & $6(20 \%)$ & $20(27 \%)$ & 0.432 \\
\hline \multicolumn{2}{|l|}{ NIS reflex abnormality } & median $=6$, range $0-20$ & median $=8$, range $0-20$ & 0.543 \\
\hline \multicolumn{2}{|c|}{ NIS sensory abnormality } & median $=7$, range $2-26$ & median $=10$, range $2-32$ & 0.352 \\
\hline \multicolumn{2}{|l|}{ NIS motor abnormality } & median $=7$, range $0-46$ & median $=8$, range $0-64$ & 0.442 \\
\hline \multicolumn{2}{|c|}{$\begin{array}{l}\text { Duration (yrs.) of symptoms prior to } \\
\text { NCS }\end{array}$} & $\begin{array}{l}\text { median }=2.0, \text { range } 0.1- \\
20.0\end{array}$ & $\begin{array}{l}\text { median }=3.0, \text { range } 0.2- \\
29\end{array}$ & 0.329 \\
\hline
\end{tabular}

NIS=Neuropathy Impairment Score; NCS= Nerve Conduction Studies 
Table 2: Significant nerve conduction and hematologic differences of WM vs IgM-MGUS

\begin{tabular}{l|l|l|l|l}
\hline \multicolumn{2}{l|}{} & WM & IgM-MGUS & p-value \\
\hline \multicolumn{2}{l|}{$\begin{array}{l}\text { Demyelinating nerve conductions } \\
\text { (28) }\end{array}$} & $8 / 30(27 \%)$ & $45 / 73(62 \%)$ & 0.001 \\
\hline $\begin{array}{l}\text { Nerve } \\
\text { conduction } \\
\text { study }\end{array}$ & Ulnar & $\begin{array}{l}\mathrm{N}=27 \\
\text { median 1.72, } \\
\text { range 1.22-6.46 }\end{array}$ & $\begin{array}{l}\mathrm{N}=70 \\
\text { median 2.43, } \\
\text { range 1.70-7.43 }\end{array}$ & $0.009^{*}$ \\
\hline & $\mathrm{RL}^{(19)}$ & $\begin{array}{l}\mathrm{N}=30 \\
\text { median 11.8, } \\
\text { range 7.3-14.5 }\end{array}$ & $\begin{array}{l}\mathrm{N}=73 \\
\text { median 14.4, } \\
\text { range 7.4-18.0 }\end{array}$ & $<0.001$ \\
$\begin{array}{l}\text { Hematologic } \\
\text { findings }\end{array}$ & $\begin{array}{l}\text { Hemoglobin } \\
\text { (gm/dl) }\end{array}$ & $\begin{array}{l}\mathrm{N}=30 \\
\text { median 3100, } \\
\text { range 658-6360 }\end{array}$ & $\begin{array}{l}\mathrm{N}=73 \\
\text { median 650, } \\
\text { range 169-2960 }\end{array}$ & $<0.001$ \\
\hline
\end{tabular}

Shown are statistically significant differences: NIS =neuropathy impairment score: $\mathrm{RL}=$ residual latency; No response conduction responses are not included in the calculations. *Multiple regression analysis was not significant for ulnar RL.

semi-quantification using a 0-4 plus scale of each of these parameters was utilized ${ }^{32}$. Zero is normal and 4 are the most affected for fibrillations and motor unit parameters of amplitude, duration and recruitment.

In further review of neuropathic features available, sural nerve biopsies, including paraffin and epoxy embedded sections and by teased fiber preparations, were reviewed. Characterization of axonal and demyelinating features of whole sural nerve biopsy was determined using standard techniques ${ }^{33}$.

\section{Autonomic testing}

Available autonomic reflex testing including study of cardiovagal, adrenergic, and sudomotor functions were reviewed by standard techniques ${ }^{24,25}$.

\section{Statistical analysis}

Descriptive statistics were used to assess for clinical, electrophysiologic, and other features of the neuropathies of WM and IgM-MGUS. Two tailed test and $\mathrm{p}<0.05$ were used to determine significant differences. Associations between the presence of WM and putative risk covariates were evaluated by Student's t-test or Wilcoxon Rank-Sum test for continuous variables and with Chi-square test or Fisher's exact test for nominal variables. Multiple logistic regression analysis was performed for evaluating the importance of neuropathy type in establishing the probability of developing WM with IgM. Multivariate two-step logistic regression models for the presence of WM were also performed to create cut-off values for predictive purposes of individual nerve conductions and hematologic parameters found significant in the total cohort.

\section{RESUlts}

The disease characteristics of the $30 \mathrm{WM}$ and 73 IgM-MGUS neuropathy patients are given in Tables 1-3. Among both groups, "numb toes and feet" was the most common chief complaint with "tremor" the second most common occurring in $10 \%$ or less of both groups. Romberg's sign and presence of tremor were not significantly different between WM and IgM-MGUS. Between the two diseases, there was no significant difference in gender, age, duration of symptoms and severity of peripheral neuropathy as determined by NIS. A significant difference was not found between diseases for motor, sensory and reflex abnormalities. Autonomic reflex screens were performed on $11 \mathrm{WM}$ and 26 IgM-MGUS patients and all showed normal adrenergic, cardiovagal function and only slight sudomotor abnormalities not significantly different between the two groups ${ }^{25}$.

Using the standard electrophysiological criteria described in the method section, demyelination was found more frequently in IgM-MGUS $(62 \%)$ than in WM $(27 \%)(p=0.001)$. The specialized NCS calculations (motor TLI and RL) also showed that ulnar-RL was significantly greater in IgM-MGUS $(\mathrm{p}=0.009)$ which is consistent with distal slowing, although ulnar-TLI,

Table 3: Assessment of axonal loss by summated motor and sensory nerve conduction amplitudes in WM, IGM-MGUS, and healthy subjects

\begin{tabular}{|c|c|c|c|c|c|c|}
\hline & $\begin{array}{l}\text { WM } \\
(\mathrm{N}=30)\end{array}$ & $\begin{array}{l}\text { IgM-MGUS } \\
(\mathrm{N}=73)\end{array}$ & $\begin{array}{l}\text { Healthy } \\
\text { subjects }\end{array}$ & $\begin{array}{l}\text { WM vs } \\
\text { healthy } \\
\text { subjects }\end{array}$ & $\begin{array}{l}\text { IgM-MGUS } \\
\text { vs healthy } \\
\text { subjects }\end{array}$ & $\begin{array}{l}\text { IgM-MGUS } \\
\text { vs WM }\end{array}$ \\
\hline $\begin{array}{l}\text { CMAPs }^{*} \\
\text { Percentiles } \\
\text { of mean } \\
\text { (range) }\end{array}$ & $\begin{array}{l}8.08 \\
(0.06-40.79)\end{array}$ & $\begin{array}{l}6.34 \\
(0.03-85.15)\end{array}$ & $\begin{array}{l}50.92 \\
(3.22-96.86)\end{array}$ & $P<0.001$ & $P<0.001$ & $p=0.419$ \\
\hline $\begin{array}{l}\text { SNAPs }^{*} \\
\text { Percentiles } \\
\text { of mean } \\
\text { (range) }\end{array}$ & $\begin{array}{l}0.09 \\
(0.03-17.23)\end{array}$ & $\begin{array}{l}0.20 \\
(0.03-53.59)\end{array}$ & $\begin{array}{l}49.48 \\
(0.70-98.66)\end{array}$ & $P<0.001$ & $P<0.001$ & $p=0.376$ \\
\hline
\end{tabular}

*The mean of mean values of summed ulnar, peroneal, and tibial compound motor action potential (CMAPs) (mV) or median and sural sensory sensory nerve action potential (SNAPs)' corrected for age, gender, height and weight as compared to reference values of healthy subjects (29-31). 

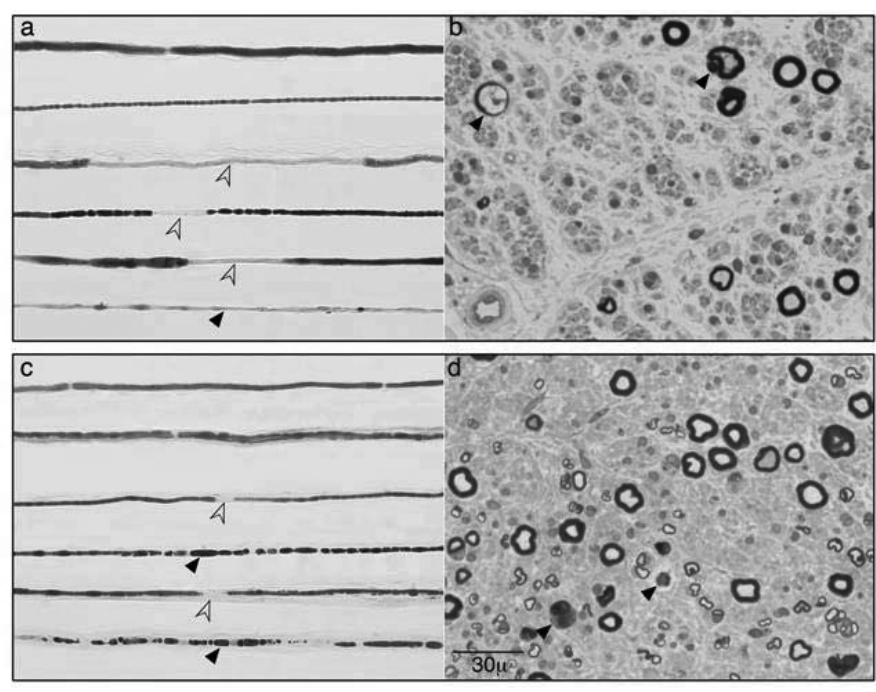

Figure: Teased and epoxy embedded sections from representative sural nerve biopsies of a patient with IgM-MGUS $(a, b)$ and Waldenström's macroglobulinemia $(W M)(c, d)$ neuropathy. Both biopsies show combination axonal fiber loss and degeneration (black arrows) with de and remyelination (open arrows). By the electrophysiologic criteria ${ }^{28}$ the shown IgM-MGUS patient had demyelinating features with axonal loss whereas the WM patient had axonal nerve conductions despite occasional demyelinating teased fibers. Both these patients presented with insidious onset sensory gait ataxia without pain or significant weakness.

median, peroneal and tibial RL as well as TLI did not reach significant difference between these two groups. Hemoglobin, $\operatorname{IgG}$ and $\operatorname{Ig} \mathrm{A}$ levels were all significantly reduced while $\operatorname{IgM}$ levels were significantly elevated in WM group compared to IgM-MGUS group. The multiple logistic regression analysis showed demyelinating findings in IgM-MGUS were significant (odds ratio $=11.1, \mathrm{p}=0.005$ ). In contrast, ulnar-RL did not reach significance with multivariate regression analysis, suggesting ulnar-RL may be correlated with the other factors.

Table 4: Assessment of axonal loss by summated needle EMG abnormalities WM vs IgM-MGUS

\begin{tabular}{|c|c|c|c|c|c|}
\hline & \multicolumn{2}{|c|}{$\begin{array}{l}\text { WM } \\
(\mathrm{N}=30)\end{array}$} & \multicolumn{2}{|c|}{$\begin{array}{l}\text { IgM-MGUS } \\
(\mathrm{N}=73)\end{array}$} & \multirow{2}{*}{$\begin{array}{l}\text { WM vs } \\
\text { IgM-MGUS } \\
\text { p-value }\end{array}$} \\
\hline & Median & Range & Median & Range & \\
\hline $\begin{array}{l}\text { Motor unit } \\
\text { potentials* }\end{array}$ & 8 & $0-18$ & 6 & $0-24$ & 0.327 \\
\hline Fibrillations* & 2 & $0-10$ & 2.5 & $0-8$ & 0.525 \\
\hline
\end{tabular}

*Summated tibialis anterior, medial gastrocnemius, vastus medialis muscle EMG abnormalities (studied in all patients) for motor unit amplitude, duration, recruitment or fibrillation abnormalities using semi quantification plus scale $(0-4,0=$ normal, $4=$ most severely affected) summed in routine needle $\mathrm{EMG}^{32}$.
The degree of axonal loss was not significantly different between IgM-MGUS and WM determined by composite score of motor and sensory CMAPs (Table 3); summated needle EMG abnormalities (Table 4); and by available nerve biopsies (Table 5) and the Figure. Summated deficits of tibialis anterior, medial gastrocnemius, vastus medialis or vastus lateralis muscles were not significantly different between IgM-MGUS and WM.

Further analysis of hematologic parameters by calculating the area under the ROC curve (AUC) suggested two predictive values for WM including a hemoglobin level less than $12.6 \mathrm{~g} / \mathrm{dl}$ (anemia) [71\% sensitivity; $88 \%$ specificity, $\mathrm{p}<0.001$ ] and IgM level greater than $1830 \mathrm{mg} / \mathrm{dl}$ [85\% sensitivity; 93\% specificity, $\mathrm{p}<0.001]$. The predictability of the hematologic cut-off values were independent of nerve conduction status, these values achieved the same specificity and sensitivity in axonal IgMMGUS and demyelinating WM. Individual nerve conduction parameters (RL, TLI) were also analyzed using AUC calculation. The only statistically significant predictive value for WM was an ulnar -RL less than 0.43 [89\% sensitive; $44 \%$ specific, $\mathrm{p}=0.0311]$.

\section{Discussion}

The distinction of IgM-MGUS from WM is important but complex. Previous studies have shown that the prevalence of IgM-MGUS is higher in familial occurrence of WM, but there is no evidence that IgM-MGUS progresses to WM with each appearing to be a different disease from their onset ${ }^{34}$.

In this retrospective study, we found that $73 \%$ of bone marrow biopsy confirmed WM patients had only primary axonal features on nerve conductions whereas 62\% of IgM-MGUS patients had demyelinating features. Despite apparent demyelinating nerve conduction differences the clinical presentations were similar. The main presenting complaint of

Table 5: Teased fiber nerve preparations for WM and IgMMGUS

\begin{tabular}{|c|c|c|c|c|c|c|c|}
\hline & \multicolumn{2}{|c|}{$\begin{array}{l}\text { WM } \\
(N=4)\end{array}$} & \multicolumn{2}{|c|}{$\begin{array}{l}\text { IgM-MGUS } \\
(\mathrm{N}=12)\end{array}$} & \multirow{2}{*}{$\begin{array}{l}\text { WM vs } \\
\text { IgM-MGUS } \\
\text { p-value }\end{array}$} & \multicolumn{2}{|c|}{$\begin{array}{l}\text { Healthy controls } \\
(\mathrm{N}=14)\end{array}$} \\
\hline & Median & Range & Median & Range & & Median & Range \\
\hline Normal A, B (\%) & 73 & $65-82$ & 50 & $25-82$ & 0.016 & 85.1 & $72-95$ \\
\hline $\begin{array}{l}\text { Demyelination C, D } \\
(\%)\end{array}$ & 10 & $5-20$ & 11 & $1-37$ & 0.800 & 0.0 & $0-2$ \\
\hline $\begin{array}{l}\text { Axonal Degeneration } \\
\mathrm{E}, \mathrm{H}(\%)\end{array}$ & 4 & $3-5$ & 4 & $2-29$ & 0.700 & 0.0 & $0-3$ \\
\hline $\begin{array}{l}\text { Remyelination } F, G \\
(\%)\end{array}$ & 10 & $10-10$ & 16 & $3-25$ & 0.480 & 13.7 & $5-28$ \\
\hline $\begin{array}{l}\text { Axon loss by empty } \\
\text { strands (number) }\end{array}$ & 30 & $15-40$ & 35 & $3-45$ & 0.470 & 6.0 & $0-19$ \\
\hline
\end{tabular}

Teased fiber types: $\mathrm{A}=$ normal, $\mathrm{B}=$ myelin wrinkling, $\mathrm{C}=$ demyelination, $\mathrm{D}=$ demyelination and remyelination, $\mathrm{E}=$ axonal degeneration, $\mathrm{F}$ = remyelination, $\mathrm{G}=$ myelin reduplication, $\mathrm{H}$ = regeneration after axonal degeneration, empty $=$ strands with loss of fibers. 
distal sensory loss and gait ataxia and similar and not infrequent occurrence of tremor was indistinguishable. Those similar impairments and severity of impairments likely relate to the comparable amounts of axonal loss seen in both groups, i.e. a mixed demyelinating-axonal pathogenesis. The apparent axonal predominant changes in WM patients do not appear related to symptom duration. Specifically, axonal features in WM related neuropathy are unlikely a simple evolution of demyelinating to axonal features as the length of time from symptom onset did not correlate with the type of nerve conduction abnormality. The more common occurrence of demyelination in our IgM-MGUS group over WM group is consistent with earlier observations without report of bone marrow biopsy ${ }^{4,5}$.

Our findings emphasize the complexity of electrophysiologic presentations in these two primary IgM hematologic disorders. The divergent electrophysiologic findings lead to speculation that a spectrum of immunity is responsible with overlap between some. The careful exam of the other aspects of clinical presentation such as the levels of hemoglobin and IgM can also provide assistance in distinguishing WM from IgM-MGUS and deciding whether to perform bone marrow biopsy. Specifically our study showed that using the cut-off level of IgM greater than $1830 \mathrm{mg} / \mathrm{dl}$ and hemoglobin level less than $12.6 \mathrm{~g} / \mathrm{dl}$ (anemia) can achieve $71 \%$ of sensitivity and $88 \%$ specificity for predicting WM cases independent of nerve conduction status. The fact that markedly elevated IgM level and anemia are more frequent in WM than in IgM-MUGS is also supported by previous study ${ }^{35}$.

The significant association of distal slowing came from only the results of the ulnar-RL in distinction of IgM-MGUS from WM. That association did not bear out with multiple regression analysis and in other nerves suggesting possible outlier statistical phenomena. Similarly we did not find reduced median-TLI significantly associated with IgM-MGUS as had been suggested in the earlier reports ${ }^{8,9}$. This difference may be due to the fact that earlier described samples used for the TLI association analysis were tested positive with anti-myelin associated glycoprotein assay, of which the occurrence may select for a specific distal phenomenon. We used retrospective study design, with this antibody not routinely tested at our institution, and therefore do not have the status of $\operatorname{IgM}$ antibodies against MAG, ${ }^{9-11}$ suggesting reduced TLI is not associated with patients without anti-MAG.

\section{Conclusions}

What are the practical implications of our findings? In cases where $\operatorname{IgM}$ monoclonal proteins are found in neuropathy patients, an axonopathy on NCS favors the diagnosis of WM over IgM-MGUS, especially if the neuropathy associates with anemia and elevated IgM concentration. Therefore, bone marrow biopsy would be more likely to yield positive WM diagnosis in the presence of axonal features. However, if the electrophysiology reveals evidence of demyelination, the decision to advance to bone marrow confirmatory diagnosis of WM should not be excluded, especially if anemia or other worrisome features are present. The decision to advance to BM should remain for those where the extent of neurologic or hematologic involvements would warrant therapeutic approaches. Based on this study, individual NCS parameters such as TLI and RL may not be as helpful, with comprehensive NCS being more helpful.

A spectrum of divergent and shared immune mechanism is implicated by both the similar and different clinical and electrophysiological features identified in WM and IgM-MGUS. Future prospective studies looking to identify the implicated varied immune paraneoplastic or paraimmune neuropathy mechanisms will be important.

\section{ACKNOWLEDGMENT}

The authors thank the Mayo Center for Translational Science Activities (CTSA), Ms. Susanna R. Stevens, and in the Peripheral Nerve Lab Ms. Jenny Davies for statistical analysis.

\section{REFERENCES}

1. Kyle RA. Neuropathy associated with the monoclonal gammopathies. In: Noseworthy JH, editor. Neurologic therapeautics: principles and practice. London, New York: Martin Dunitz; 2003. p. 2126-36.

2. Lozeron P, Adams D. Monoclonal gammopathy and neuropathy. Curr Opin Neurol. 2007 Oct;20(5):536-41.

3. Katz JS, Saperstein DS, Gronseth G, Amato AA, Barohn RJ. Distal acquired demyelinating symmetric neuropathy. Neurology. 2000;54:615-20.

4. Levine T, Pestronk A, Florence J, et al. Peripheral neuropathies in Waldenstrom's macroglobulinaemia. J Neurol Neurosurg Psychiatry. 2006 Feb;77(2):224-8.

5. Baldini L, Nobile-Orazio E, Guffanti A, et al. Peripheral neuropathy in IgM monoclonal gammopathy and Waldenstrom's macroglobulinemia: a frequent complication in elderly males with low MAG-reacitve serum monoclonal component. Am J Hematol. 1994;45:25-31.

6. Owen RG, Treon SP, Al-Katib A, et al. Clinicopathological definition of Waldenstrom's macroglobulinemia: consensus panel recommendations from the Second International Workshop on Waldenstrom's Macroglobulinemia. Semin Oncol. 2003 Apr;30(2):110-5.

7. Gertz MA. Waldenstrom macroglobulinemia: a review of therapy. Am J Hematol. 2005 Jun; 79(2):147-57.

8. Kaku DA, England JD, Sumner AJ. Distal accentuation of conduction slowing in polyneuropathy associated with antibodies to myelin-associated glycoprotein and sulphated glucuronyl paragloboside. Brain. 1994 Oct;117(Pt 5):941-7.

9. Lupu VD, Mora CA, Dambrosia J, Meer J, Dalakas M, Floeter MK. Terminal latency index in neuropathy with antibodies against myelin-associated glycoproteins. Muscle Nerve. 2007 Feb;35 (2):196-202.

10. Capasso M, Torrieri F, Di Muzio A, De Angelis MV, Lugaresi A, Uncini A. Can electrophysiology differentiate polyneuropathy with anti-MAG/SGPG antibodies from chronic inflammatory demyelinating polyneuropathy? Clin Neurophysiol. 2002 Mar; 113(3):346-53.

11. Attarian S, Azulay JP, Boucraut J, Escande N, Pouget J. Terminal latency index and modified $\mathrm{F}$ ratio in distinction of chronic demyelinating neuropathies. Clin Neurophysiol. 2001 Mar;112 (3):457-63.

12. Bain PG, Britton TC, Jenkins IH, et al. Tremor associated with benign IgM paraproteinaemic neuropathy. Brain. 1996 Jun;119 (Pt 3):789-99.

13. Gabriel JM, Erne B, Miescher GC, et al. Selective loss of myelinassociated glycoprotein from myelin correlates with anti-MAG antibody titre in demyelinating paraproteinaemic polyneuropathy. Brain. 1996;119:775-87.

14. Hays AP, Latov N, Takatsu M, Sherman WH. Experimental demyelination of nerve induced by serum of patients with neuropathy and an anti-MAG IgM M-protein. Neurology. 1987 Feb;37(2):242-56. 
15. Tatum AH. Experimental paraprotein neuropathy, demyelination by passive transfer of human $\operatorname{IgM}$ anti-myelin-associated glycoprotein. Ann Neurol. 1993 May;33(5):502-6.

16. Gosselin S, Kyle RA, Dyck PJ. Neuropathy associated with monoclonal gammopathies of undetermined significance. Ann Neurol. 1991;30:54-61.

17. Suarez GA, Kelley JJ. Polyneuropathy associated with monoclonal gammopathy of undetermined significance: Further evidence that IgM-MGUS neuropathies are different than IgG-MGUS. Neurology. 1993;43:1304-8.

18. Garces-Sanchez M, Dyck PJ, Kyle RA, et al. Antibodies to myelinassociated glycoprotein (anti-Mag) in IgM amyloidosis may influence expression of neuropathy in rare patients. Muscle Nerve. 2008 Apr;37(4):490-5.

19. Kraft GH, Halvorson GA. Median nerve residual latency: normal value and use in diagnosis of carpal tunnel syndrome. Arch Phys Med Rehabil. 1983 May;64(5):221-6.

20. Radziwill AJ, Steck AJ, Renaud S, Fuhr P. Distal motor latency and residual latency as sensitive markers of anti-MAG polyneuropathy. J Neurol. 2003 Aug;250(8):962-6.

21. Shahani B, Young R, Potts F, Maccabee P. Terminal latency index (TLI) and late response studies in motor neuron disease (MND), peripheral neuropathies and entrapment syndromes (abstract). Acta Neurol Scand. 1979; Supp 73:118.

22. Mauermann ML, Burns TM. Pearls and Oysters: evaluation of peripheral neuropathies. Neurology. 2009 Feb 10;72(6):e28-31.

23. Dyck PJ, Dyck PJB, Chalk CH. The 10 P's: a mnemonic helpful in characterization and differential diagnosis of peripheral neuropathy. Neurology. 1992;42:14-8.

24. Low PA, Benarroch EE. Clinical autonomic disorders: Philadelphia. Wolters Kluwer; 2008.

25. Low PA. Composite autonomic scoring scale for laboratory quantification of generalized autonomic failure. Mayo Clin Proc. 1993 Aug;68(8):748-52.
26. Dyck PJ, Sherman WR, Hallcher LM, et al. Human diabetic endoneurial sorbitol, fructose, and myo-inositol related to sural nerve morphometry. Ann Neurol. 1980;8(6):590-6.

27. Daube J. Clinical Neurophysiology. 1st ed. Philadelphia: Davis; 1996.

28. Research criteria for diagnosis of chronic inflammatory demyelinating polyneuropathy (CIDP). Report from an Ad Hoc Subcommittee of the American Academy of Neurology AIDS Task Force. Neurology. 1991 May;41(5):617-8.

29. Dyck PJ, O'Brien PC, Litchy WJ, Harper CM, Daube JR, Dyck PJB. Use of percentiles and normal deviates to express nerve conduction and other test abnormalities. Muscle Nerve. 2001; 24:307-10.

30. Dyck PJ, Litchy WJ, Lehman KA, Hokanson JL, Low PA, O'Brien PC. Variables influencing neuropathic endpoints: the Rochester Diabetic Neuropathy Study of Healthy Subjects. Neurology. 1995 Jun;45(6):1115-21.

31. O'Brien PC, Dyck PJ. Procedures for setting normal values. Neurology. 1995 Jan;45(1):17-23.

32. Daube JR. Clinical neurophysiology (CD disc monogram of EMG needle examination). New York: Oxford University Press; 2009.

33. Dyck PJ, Dyck PJB, Giannini C, Sahenk Z, AJ W, Engelstad J. Peripheral nerves. In: Graham DI, Lantos PL, editors. Greenfields Neuropathology. London: Oxford University Press; 2002. p. 551-675.

34. McMaster ML, Kristinsson SY, Turesson I, Bjorkholm M, Landgren $\mathrm{O}$. Novel aspects pertaining to the relationship of Waldenstrom's macroglobulinemia, IgM monoclonal gammopathy of undetermined significance, polyclonal gammopathy, and hypoglobulinemia. Clin Lymphoma Myeloma. 2009 Mar;9 (1):19-22.

35. Facon T, Brouillard M, Duhamel A, et al. Prognostic factors in Waldenstrom's macroglobulinemia: a report of 167 cases. J Clin Oncol. 1993 Aug;11(8):1553-8. 